\title{
Gamification - tools for learning foreign languages
}

\author{
Daria Valerievna Sukhorukova* and Natalya Vladimirovna Chernyishkova \\ Financial University under the Government of the Russian Federation, Department of Foreign \\ Languages and Intercultural Communication of Moscow, Russia
}

\begin{abstract}
Gamification is an approach that creates multiple opportunities for teachers to improve a foreign language lesson. Even though now gamification is widely used as a result of a forced switch to distance learning, it should be noted that it carries the same value inside a classroom and makes the learning process enjoyable and effective. The article looks at three specific websites/applications that are aimed at incorporating new elements into a traditional classroom. These tools have different features the amount of time one spends preparing a task can vary - but all three can increase the degree of involvement and motivation which are two factors that may predetermine the success and effectiveness of a class. The article delves into aspects of motivation and its importance in a real classroom and in an online one. It is an essential factor to consider because everyone who is involved in an educational process contributes to its success. That is why if a teacher is energetic, eager and ready, and students are at the other end of the spectrum (or vice versa), so the overall motivation is not at $100 \%$, it turns a lesson into a challenge, and not in a good way.
\end{abstract}

Keywords: gamification, distance learning, higher education, motivation, website, application, digitalisation

\section{Introduction}

Since early 2020 educators all over the world had to face a common problem - lack of motivation among students because of the switch to distance learning. The process of distance learning creates additional challenges to the ones that are omnipresent in any classroom.

Firstly, it is necessary to look at the ways of presenting and controlling the progress of each student. It is already difficult to do this in traditional context, with distance learning this intensifies and demands a new approach to how a teacher introduces a topic, how it is discussed, what exercises to do and how they are to be done, and lastly, how a teacher monitors all of these steps [1].

This leads to a second issue - the organisation of the learning process. Even if all students have their cameras on, a teacher cannot rely on traditional process, an important part of which is real-life communication. An educator needs to work out a way to include

*Corresponding author: $\underline{\text { dvsuhorukova@.fa.ru }}$ 
all the necessary components of a traditional class online but make it logical and achieve cooperation among all the participants [2].

A third important aspect of distance learning is common desire to succeed. High motivation should be seen as a given in distance learning, without it nothing will work. [3]

These three aspects of successful foreign language learning will be looked at through the prism of gamification that encompasses a variety of specific tools aimed at making the whole process not only enjoyable but also effective - both in classroom and at home in front of a device.

\section{$2 \quad$ Methods}

Gamification is gradually becoming a constant element of the process of learning foreign languages [4]. Even though its popularity has spiked because of the switch to distance learning, it is also viewed as an effective element inside a real classroom ('blended learning') [5]. The article looks at different online resources that create an opportunity to incorporate gamification into a foreign language classroom - online and "offline".

Table 1 represents the results of the analysis of three resources - Wordwall, Quizlet and TriviaMaker - in terms of their effectiveness at different stages of a lesson. There are two stages 'Lead-in' and 'Presentation' that are considered not appropriate when it comes to these specific websites/applications. For example, 'lead-in' is usually very short and requires an oral monologue or a quick oral task - a link to the previous material. All the other stages shown in the table seem to be ideal circumstances for introducing gamification into a foreign language classroom.

Table 1. Analysis of effectiveness.

\begin{tabular}{|l|c|c|c|}
\hline \multicolumn{1}{|c|}{ Lesson Stages } & Wordwall & Quizlet & TriviaMaker \\
\hline Lead-in & - & - & - \\
\hline Elicitation & + & + & + \\
\hline Presentation & - & - & - \\
\hline Controlled Practice & + & + & + \\
\hline Freer Practice & + & + & $+/-$ \\
\hline Review and Follow-up & + & + & + \\
\hline
\end{tabular}

Table 2 demonstrates the similarities and differences these websites have that influence their effectiveness. The understanding of these characteristics allows to find the best combination of available tools for each teacher / topic / student etc.

Table 2. Websites characteristics.

\begin{tabular}{|l|c|c|c|}
\hline \multicolumn{1}{|c|}{ Features } & Wordwall & Quizlet & TriviaMaker \\
\hline Time Consuming & + & $+/-$ & + \\
\hline Format Variety & High & High & Low \\
\hline Applicable to Homework & + & + & - \\
\hline Customisation & + & + & + \\
\hline Free Access & $\begin{array}{c}+ \\
\text { (limited number of } \\
\text { formats) }\end{array}$ & $\begin{array}{c}+ \\
\text { (limited number of } \\
\text { features) }\end{array}$ & + \\
\hline For Individual/Group Use & Mostly Individual & Both & Mostly Group \\
\hline
\end{tabular}

The tables were created based on the authors' experience of teaching English and French at a university and reflect what needs to be taken into account while deciding on the way these gamification tools are included in the learning process. 


\section{$3 \quad$ Results}

The article focuses on the analysis of three application/websites - Wordwall, Quizlet and TriviaMaker. All three are web-based; plus, Quizlet and TriviaMaker are available as a phone application.

We have looked at standard division into stages that does not have to be used all the time. The lead-in to any lesson is usually something short, maximum 5 minutes, and the use of any of online sources would be illogical because there would be no correlation between the time and effort put into the creation of an online task and the time dedicated to actually doing it.

The presentation stage requires a different website or application or programme, for example, Power Point or Padlet, something that is specifically aimed at the action of presenting the new material. Therefore, the authors do not consider the given applications suitable.

The other four stages create good conditions for using gamification. Elicitation presupposes a higher degree of involvement from the students because a teacher hopes to extract what they already know on the topic. In this case, TriviaMaker helps to do it in the form of a game show that is called Family Feud. Through Quizlet a teacher can prepare a list of words that the system uses to create an online game; and Wordwall presents multiple opportunities to prepare a task to evaluate the level of knowledge on this topic.

Then Controlled Practice and Freer Practice are the stages with fewer constraints, which means that a variety of applications, including these three, can be effectively employed to work with the new material, look at it from different angles and even eliminate gaps after explanation.

Review and Follow-Up also create prerequisites for the use of all these three applications. For revising at home, TriviaMaker is not the best option because it is designed for team competition, that is why it would be boring for students to use it on their own. As for Quizlet and Wordwall - they are both applicable in class and at home. With Wordwall a teacher gets an opportunity to see each student's result; Quizlet requires less effort - one only creates a list (words + definitions), and the system prepares several tasks [6].

The results reflected in Table 2 present a comparative analysis of three tools to choose from for a specific educational context. Here is a brief breakdown of the amount of time a teacher needs to spend on preparing different tasks. Creating one task in Wordwall (a crossword or a 'fill in the gaps' task) will take about 15-25 minutes, which will lead to students performing a task individually (in class or at home) and the teacher having the results ready in the system. There is no need to check; plus, students can redo the task. Quizlet allows to spend less time: a teacher just needs to enter a list that can have different forms - term + definition, term + translation, term + synonym/antonym, etc. [7]. Usually, it will take 20 minutes, and then students can learn the vocabulary through the exercises made by the system. In its turn, TriviaMaker will take up to 30 minutes, and as a result, a teacher has a game that will last for 30-45 minutes.

\section{Discussion}

Gamification is an important aspect of today's learning for several reasons. Firstly, with each year students are more and more developed technology-wise [8]. They are used to always being with a device and getting information from it. Therefore, if a teacher aspires 
to engage students into the learning process, he/she needs to accept the role of technology and use it to his/her advantage.

Secondly, gamification has become an even more viable option because of distance learning. The tools that demonstrate the degree of every student's involvement compensate for an evident lack of real communication [9]. Through online tasks, a teacher can regulate the process effectively. In a real classroom students and a teacher are actually physically together, so they are a part of the whole process. In the online format, students lose this sense of togetherness (cameras help but only partially) [10]. To recreate this atmosphere a teacher can make use of gamification tools, for example, Quizlet has a live game option (individually or in teams), and during the game, you can demonstrate the screen with a live scoreboard [11].

A third reason for the importance of gamification integration in a foreign language classroom is connected with motivation. In any educational context, a teacher requires a high level of motivation from students and needs to clearly understand how to influence it [12]. In an ideal one, a teacher is ready and $100 \%$ motivated to give their best and students are $100 \%$ interested, eager to listen and understand, they are focused and do everything they are told. In reality, though, there are many factors that influence the whole process [13].

In an educational context, motivation depends on a teacher's personality, on the tempo, on discipline - including strict timing for doing tasks, on understanding the roles played by participants (a teacher and students) and on the way of presenting and working with the material [14]. Understanding the way these factors are connected with a specific type of motivation - internal or external - is essential in a foreign language classroom - it predetermines successful acquisition of the language. Internal motivation is naturally more valuable and in terms foreign language learning it comprises communicative motivation (innate need to communicate) and motivation created "inside" the educational process [15]. As for external motivation, it includes social motivation (desire to achieve a certain social status or to be like others) and motivation predetermined by future prospects (for instance, getting a job) [16].

Four approaches can facilitate the process of increasing motivation: inclusion of cultural aspect of a foreign language, imitation of future professional activity, implementing audio and video materials (inside and outside of a classroom) and incorporating interactive educational platforms [17]. Traditional approaches - mastering intercultural skills, listening to recordings, watching videos, doing role plays and cases - have always been effective tools of increasing students' motivation and enriching an educational process [18]. However, they are not enough anymore - not only because of the forced switch to distance learning, but also because of the necessity to innovate more and more with every year [19]. Each new generation wants more, requires more. From the point of view of a teacher, it is exhausting but if one wants to keep up with new students, it is necessary to branch out, and this can be done with the help of interactive educational platforms - that is gamification. It creates a sense of newness and originality, and if mixed rationally with traditional tools, can make the process of learning a foreign language enjoyable and fulfilling.

\section{Conclusion}

In today's classroom motivation is one of the key elements that influence the whole atmosphere and the level of success and effectiveness. A teacher needs to be highly intuitive to understand the specifics of each educational context and look for ways to deal with arising issues. One of these ways is gamification that increases the degree of 
involvement of the students, brings variety into the traditional context and just allows to be a part of a digital society.

Students determine the way an educational system should work, they are quick to react if something is not done the way that they consider 'correct' or 'appropriate', and educators need to reasonably and rationally look at different aspects and find ways of creating a balanced system which will lead to a well-organised lesson [20]. New generations are born in the world of technologies, and therefore it is only logical that teachers implement them in their work. A teacher's job is to identify the best tools and determine which part of a lesson is appropriate for digitalisation.

In addition, a teacher may look for platforms that not only offer great digital educational content but also allow to create customised tasks. Educators can even go further and get involved in the creation of such platforms because they are the ones that clearly understand what is needed in a classroom and how gamification specifically and digitalization in general can facilitate the learning process and meet the requirements of both teachers and students.

\section{References}

1. S. Benini, M. Thomas, A critical review of research on gamification and second language acquisition, in M. Peterson, K. Yamazaki, M. Thomas (eds), Digital Games and Language Learning: Theory, Development and Implementation, 9-46 (Bloomsbury Academic, London, 2021). https://doi.org/10.5040/9781350133037.ch-002

2. K.L. De La Cruz, L. Noa, K. Ayca, J Devel Res, 10(10), 41787-41791 (2020). https://doi.org/10.37118/ijdr.20319.10.2020

3. Sh. Samson, S.V. Karthiga, J Early Childh Spec Edu, 12, 99-102 (2020). https://doi.org/10.9756/INT-JECSE/V12I2.201061

4. S.Y. Dronova, Mod Edu, 1, 59-70 (2021). https://doi.org/10.25136/2409-8736.2021.1.35174

5. A. Korol, O. Blashkova, V. Kravchenko, A. Khilya, Web-technologies and multimedia systems in the training of professionals in the education system. Environment.

Technologies. Resources, in Proceedings of the $13^{\text {th }}$ International Scientific and Practical Conference, 2, 244-248, Rezekne, Latvia (2021). https://doi.org/10.17770/etr2021vol2.6570

6. N. Hồng, N. Du, TNU J Sci Techn, 226, 34-42 (2021). https://doi.org/10.34238/tnu-jst.4100

7. L. Václavík, CASALC Rev, 10(1), 69-88 (2020). https://doi.org/10.5817/CASALC2020-1-6

8. V.V. Kotenko, Sci Notes Lesgaft Univ, 4(194), 226-232 (2021). https://doi.org/10.34835/issn.2308-1961.2021.4.p226-232

9. C. Cruaud, ALSIC, 21 (2018). https://doi.org/10.4000/alsic.3166

10. A.Yu. Shirokikh, World Sci, Cult Edu, 3(88), 136-139 (2021). https://doi.org/10.24412/1991-5497-2021-388-136-139

11. M. Veljkovic Michos, 511-516 (2017). https://doi.org/10.15308/Sinteza-2017-511-516

12. A.Y.vShirokikh, et al., Euras J Analyt Chem, 12(7b), 1581-1589 (2017). https://doi.org/10.12973/ejac.2017.00288a 
13. P. Putra, A. Priyatmojo, J Engl Lang Teach, 10, 21-29 (2021). https://doi.org/10.15294/elt.v10i1.40558

14. G.N. Makhmutova, Bul Fin Univ, 1(9), 75-78 (2013)

15. I.I. Klimova, G.V. Klimova, S.A. Dubinka, XLinguae, 12(1), 207-218 (2019). https://doi.org/10.18355/XL.2019.12.01.16

16. G.A. Dubinina, I.K. Stepanyan, E.V. Ganina, Espacios, 39(38) (2018)

17. T.G. Bortnikova, M.I. Dolzhenkova, Bul Tambov Univ, Human, 25(186), 34-41 (2020). https://doi.org/10.20310/1810-0201-2020-25-186-34-41

18. O.V. Meshcheryakova, Soc: Sociol, Psych, Pedag, 74, 180-186 (2020). https://doi.org/10.24158/spp.2020.6.30

19. E.A. Ganina, E.A. Fedorova, Top Iss Human Nat Sci, 1-2, 93-97 (2014)

20. T.A. Goroshnikova, E.S. Smakhtin, Interdisciplinary Curriculum Approach as a University Component for Large-scale Education Projects, in Proceedings of $201811^{\text {th }}$ International Conference; Management of Large-Scale System Development, MLSD 2018, 8551932 (2018). https://doi.org/10.1109/MLSD.2018.8551932 